A s i a $\mathrm{n}$ o u r nal of

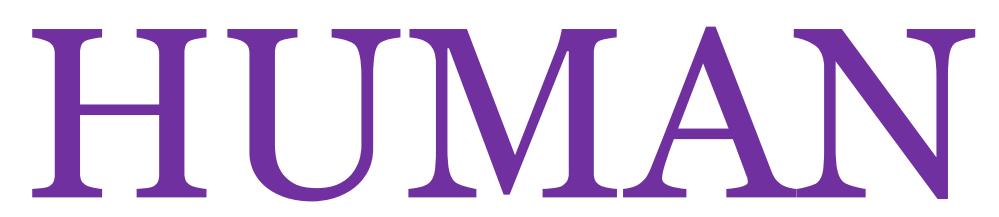

Printed 2018.1030 ISSN2188-059X

Published by Asian Society of Human Services

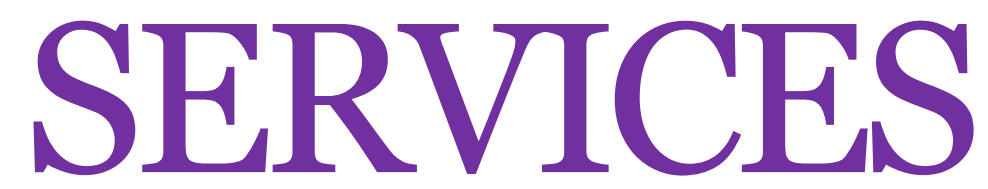

$\left.O_{\text {ctober } 2018}\right\rceil 5$
VOL.

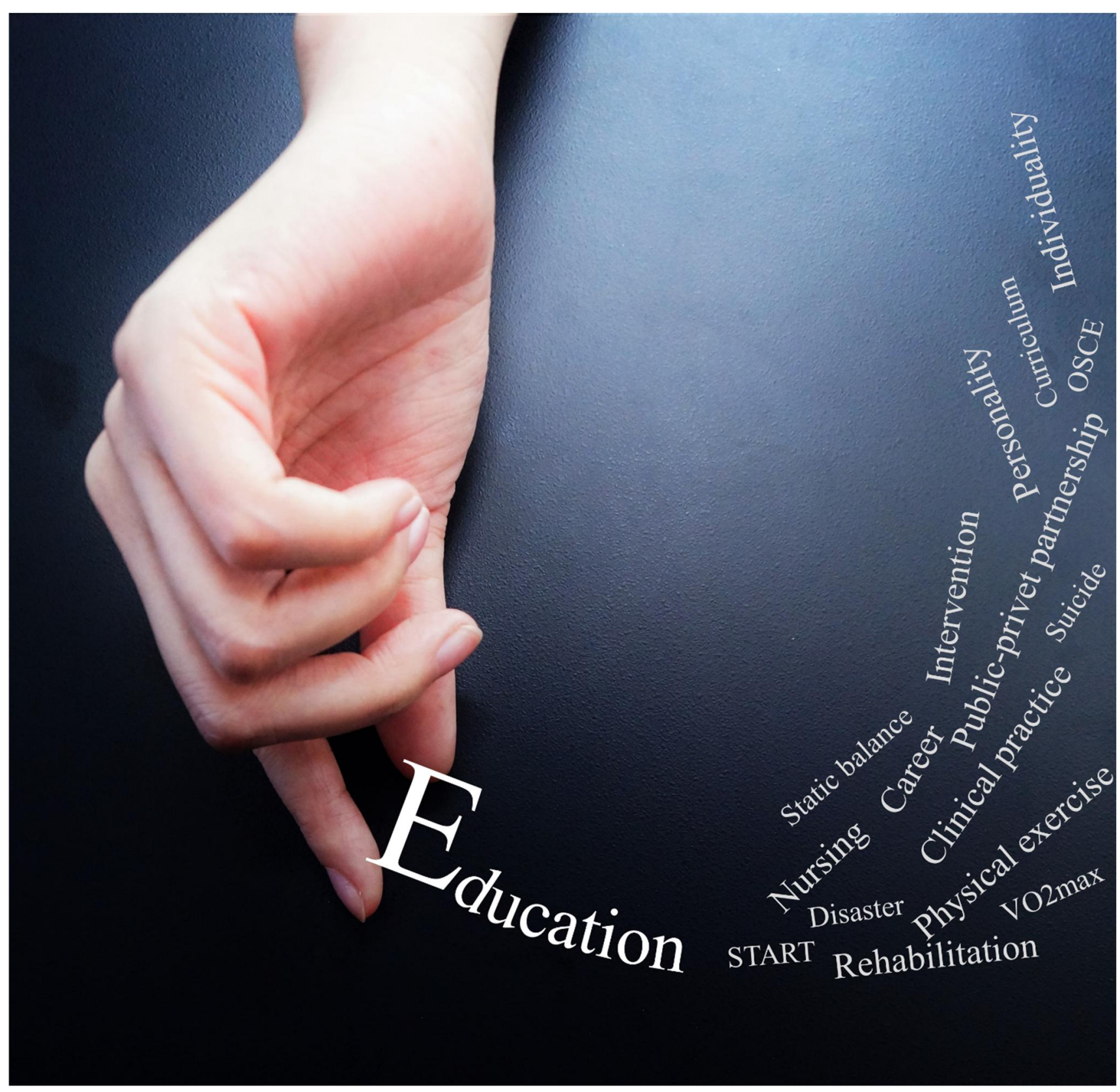




\title{
Using Videos to Analyze the Effectiveness of START Education for Japanese Nursing Students
}

\author{
Kazuyuki AKINAGA1) Kaoru SHIBAYAMA1) Koichi TAKAHASHI ${ }^{1)}$ \\ Setsuko UMEZAKI ${ }^{2}$ ) Kazue NONAKA ${ }^{1}$ ) Norihito NOGUCHI $\left.{ }^{3}\right)$ \\ Koichi SHINCHI ${ }^{1}$
}

1) Graduate School of Medical Sciences, Saga University, Japan

2) Department of Nursing, School of Health and Medical Sciences, Junshin Gakuen University, Japan
3) Department of Nursing, School of Medical Education, National Defense Medical College, Japan

\begin{abstract}
This study aims to evaluate the effectiveness of teaching START (Simple Triage and Rapid Treatment) to nursing students using videos. To this end, we conducted a study from October 1, 2016 to March 31, 2018, instructing nursing students to view a video of 30 simulated cases and to perform triage exercises both before and after START training. Subjects included 57 freshmen and 56 seniors. We calculated the accuracy rate for each case and examined those where students were most likely to make mistakes. We found that after START training, both freshmen and senior students did significantly better on the triage exercises. Before the training, seniors treated an average ( \pm standard error (SE)) of $23.5 \pm 0.7$ out of 30 patients correctly, while after the training, this number increased to $29.3 \pm 0.2(\mathrm{p}<0.001)$. For freshmen, the increase was even more drastic, increasing from $17.4 \pm 0.6$ correct before the training to $29.1 \pm 0.3$ after $(p<0.001)$. While freshmen initially answered far fewer questions correctly, after the training, there was no significant difference in the performance of freshmen and seniors: both groups had an overall accuracy rate of $95 \%$ or higher. The drastic performance increase even of freshmen with little medical knowledge suggests that this program may even be effective for the general public, making our results relevant for developing better disaster medical care in the future.
\end{abstract}

Received

April 22, 2018

Revised

June 8, 2018

Accepted

June 27, 2018

Published

October 30, 2018

$<$ Key-words $>$

disaster, education, nursing student, START

Corresponding author: shinchik@cc.saga-u.ac.jp (Koichi SHINCHI; Japan) Asian J Human Services, 2018, 15:1-12. C 2018 Asian Society of Human Services 


\section{Introduction}

Japan frequently suffers from natural disasters, including the 1995 Great HanshinAwaji Earthquake, the 2011 Great East Japan Earthquake, and the 2016 Kumamoto Earthquake. In all of these cases, while nurses helped medically treat those injured after the disaster, there was a shortage in both medical manpower and resources like medicine and supplies, especially during the first 72 hours. Triage, therefore, is a vital tool to prioritize victims' treatment and hospitalization, help the greatest number of patients possible. In cases such as the above example, the lack of doctors means that nurses are often responsible for triage (Fukuyama, Shinchi, Shinchi et al., 2006; Furukawa, Shinchi, Fukuyama et al., 2007; Ishibashi, Fukuyama, Nonaka et al., 2017; Noguchi, Inoue, Shimanoe et al., 2016). Nursing curriculum, therefore, should include triage education (Akinaga, Takahashi, Sakamoto et al., 2012; Matsunaga, Akinaga, Umezaki et al., 2013; Matsunaga, Shinchi, Akinaga et al., 2013).

Triage derives from a French word meaning "sorting" and "choosing." In medical terms, it is a technique to maximize the number of survivors after a disaster by categorizing the injured based on the severity of their wounds and prioritizing treatment and hospitalization accordingly (Donatelli \& Somes, 2012; Good, 2008; Somes \& Donatelli, 2014). Studies on triage have reported the need for regular training (Akinaga, Takahashi, Sakamoto et al., 2012; Howard \& Foley, 2014; Powers, 2007) to teach medical professionals how to engage in triage effectively.

The increased number of natural disasters makes it vital for nurses to be taught the principles of triage in disaster situations (Evans \& Baumberger-Henry, 2014); this teaching is most effective when begun through simulations during their ongoing education (Brannigan, Witwer, Rudel et al., 2006; Duarte \& Haynes, 2006; Foronda, Shubeck, Swoboda et al., 2016).

To this end, Japanese nursing colleges today provide triage education to their students. However, there are as of now few studies that examine the most effective educational methods for this training (Akinaga, Takahashi, Sakamoto et al., 2012). This study attempts to answer some of those remaining questions. Specifically, we evaluate the effectiveness of using videos to teach the START (Simple Triage and Rapid Treatment) method of triage to nursing students. This triage method was developed in 1983 by the Hoag Hospital and Newport Beach Fire Department in California and is now widely used in the United States (Benson, Koening \& Schultz, 1996; United States Department of Health and Human Services, 2018). It is a tool used by first responders to quickly classify victims during a mass casualty incident (MCI) based on the severity of their injury.

Our findings have implications for future human resource development in disaster medical care. 


\section{Methods}

We showed two groups of nursing students-a group of freshmen and a group of seniors - a video with 30 simulated cases and provided an accompanying lecture (Kawahara \& Ishida, 2008). We also asked the students to perform a triage exercise both before and after START training.

The training started with the lecture by a medical professor and doctor experienced in disaster medical treatment. Prior to beginning START training, both freshmen and seniors were told only about the basic concept and definition of triage (Sakai \& Kikuchi, 2016) and then shown the accompanying video. After the video, the professor described the START method in detail and, two hours later, students were asked to perform triage on patients with the same symptoms as in the video. Students used an answer sheet to describe the triage category of each patient using the START classification, and the answer sheets were collected after the lecture was over.

Table 1 provides details regarding the 30 simulated cases students viewed on the video and were later asked to triage. Information provided included age, gender, ability to walk on their own, whether they were breathing on their own, number of breaths per minute, capillary refilling time (nail blanch test), whether they were capable of following simple commands, heart rate, and diagnosis.

Because of the course curriculum, the lecture was given on a different day for freshmen and seniors. However, the contents of the lecture were the same for both groups and included information on the purpose of triage, situations that require triage, and how to prioritize patients. Students were also given information about the START method specifically, which involves providing each patient with a colored tag based on their triage classification: minor (green), delayed (yellow), immediate (red), or deceased (black). This classification is made based on whether a patient is capable of walking by themselves, is breathing by themselves, their respiration rate, level of consciousness, and the palpation of radial artery or capillary refilling time of the nail (CRT). 
$<$ Table $1>$ Characteristics of the 30 cases included in the video

\begin{tabular}{|c|c|c|c|c|c|c|c|c|c|c|}
\hline & Age & Sex & Diagnosis & $\begin{array}{c}\text { Triage } \\
\text { category }\end{array}$ & Walk & Breathing & \begin{tabular}{|l} 
Ventilatory \\
frequency
\end{tabular} & \begin{tabular}{|c|c|} 
capillary \\
refilling \\
time
\end{tabular} & $\begin{array}{c}\text { Verbal } \\
\text { contact }\end{array}$ & $\begin{array}{c}\text { Heart } \\
\text { rate }\end{array}$ \\
\hline 1 & Infant & female & Dead & Black & $x$ & $x$ & $\mathbf{0}$ & $x$ & $x$ & $\mathbf{0}$ \\
\hline 2 & 82 & male & Cut on the ear & Green & 0 & 0 & 23 & 0 & 0 & 75 \\
\hline 3 & 43 & female & Epidermal burn & Green & 0 & 0 & 22 & 0 & 0 & 56 \\
\hline 4 & 25 & male & Intestinal tract hernia & Red & $x$ & 0 & 23 & $x$ & 0 & 92 \\
\hline 5 & 19 & female & Blow to the head & Green & 0 & 0 & 28 & 0 & 0 & 96 \\
\hline 6 & 54 & female & Previous head abrasion & Green & 0 & 0 & 20 & 0 & 0 & 82 \\
\hline 7 & 45 & female & Right cheek abrasion & Green & 0 & 0 & 24 & 0 & 0 & 97 \\
\hline 8 & 36 & male & Left leg abrasion & Green & 0 & 0 & 21 & $x$ & 0 & 82 \\
\hline 9 & 67 & male & Myocardial infarction & Red & $x$ & 0 & 40 & 0 & 0 & 116 \\
\hline 10 & 64 & male & Radial artery damage & Green & 0 & 0 & 29 & 0 & 0 & 104 \\
\hline 11 & 8 & male & Fall & Green & 0 & 0 & 28 & 0 & 0 & 116 \\
\hline 12 & 40 & male & facial burn & Green & 0 & 0 & 24 & $x$ & 0 & 106 \\
\hline 13 & 32 & male & Crash syndrome & Red & $x$ & 0 & 32 & 0 & $\Delta$ & 84 \\
\hline 14 & 32 & female & Nose fracture & Green & 0 & 0 & 20 & 0 & 0 & 80 \\
\hline 15 & 52 & male & Head wound & Green & 0 & 0 & 20 & $x$ & 0 & 80 \\
\hline 16 & 23 & male & Pelvis fracture & Red & $x$ & 0 & 36 & 0 & 0 & 120 \\
\hline 17 & 67 & male & Finger cutting & Green & 0 & 0 & 28 & 0 & 0 & 72 \\
\hline 18 & 72 & male & Upper body burns & Yellow & $x$ & 0 & 28 & 0 & 0 & 112 \\
\hline 19 & 36 & female & Cervical sprain & Green & 0 & 0 & 24 & 0 & 0 & 78 \\
\hline 20 & 71 & male & Eye puncture & Green & 0 & 0 & 24 & 0 & 0 & 78 \\
\hline 21 & 43 & male & Left leg open fracture & \begin{tabular}{|l|} 
Yellow \\
\end{tabular} & $x$ & 0 & 28 & 0 & 0 & 116 \\
\hline 22 & 60 & female & $\begin{array}{l}\text { Right second finger } \\
\text { extensor tendon tear }\end{array}$ & Green & o & o & 23 & 0 & o & 92 \\
\hline 23 & 25 & male & \begin{tabular}{|c|}
$\begin{array}{c}\text { Left leg } \\
\text { second-degree } \\
\text { burn }\end{array}$ \\
\end{tabular} & Yellow & $x$ & 0 & 28 & 0 & 0 & 96 \\
\hline 24 & 28 & female & Pregnant, Water broke & Yellow & $x$ & 0 & 24 & 0 & 0 & 64 \\
\hline 25 & 21 & female & Left wrist fracture & Green & 0 & 0 & 25 & 0 & 0 & 82 \\
\hline 26 & 35 & female & Glass puncture wound & Green & 0 & 0 & 29 & 0 & 0 & 104 \\
\hline 27 & 2 & male & $\begin{array}{c}\text { Right forearm second- } \\
\text { degree burn }\end{array}$ & Yellow & $x$ & 0 & 28 & 0 & O & 92 \\
\hline 28 & 51 & female & $\begin{array}{c}\text { Blow to back of the } \\
\text { head }\end{array}$ & Green & 0 & 0 & 22 & 0 & 0 & 86 \\
\hline 29 & 10 & male & Wrist burns & Green & 0 & 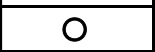 & 27 & 0 & 0 & 94 \\
\hline 30 & 78 & male & Intraoral injury & Green & 0 & 0 & 24 & 0 & 0 & 74 \\
\hline
\end{tabular}

${ }^{1}$ black $=$ deceased , red $=$ immediate, yellow $=$ delayed , green $=$ minor

$2 \circ=$ can walk, $x=$ cannot walk, ${ }^{3} \circ=$ can breathe by oneself, $x=$ cannot breathe

${ }^{4}$ times $/ \mathrm{min},{ }^{5} \circ=<2$ seconds, $x=>2$ seconds, ${ }^{6} \circ=$ yes, $x=$ no, ${ }^{7}$ times $/ \mathrm{min}$

Source: Kawahara K, et al. Disaster triage simulation education material (DVD), Tokyo Metropolitan University and Benesse Corporation (2008).

\section{Subjects}

We collected data between October 1, 2016 and March 31, 2018. Subjects included 56 senior ( 1 male, 55 females) and 57 freshmen ( 2 males, 55 females) nursing students at the Saga Medical School Faculty of Medicine. The average age of the students ( \pm standard deviation (SD)) was $18.9 \pm 0.2$ for freshmen and $21.6 \pm 0.1$ for seniors. The participation and valid response rate were $100 \%$. 
For senior students, we taught the START method as part of a lecture on disaster nursing. For freshmen students, we included our curriculum as part of a public health lecture related to disaster nursing. This occurred six months after the students were admitted, before many had attended a medical or nursing lecture.

\section{Ethical Consideration}

The study passed Saga University Faculty of Medicine's ethical review (approval number: 28-38). We did not require students to include personal information, such as their name or student number, on the answer sheets. We explained the purpose of the study to the students and assured them that refusing to participate or discontinuing halfway through would not adversely affect their grades. All students agreed to participation by submitting their answer sheet for the triage classification exercises.

\section{Data Analysis}

We analyzed the answers to the triage exercises both before and after START training based on students' age, gender, and number of questions correct (out of 30) using SPSS statistics 23 .

There was no standard normal distribution of correct answers for either freshmen or seniors. We compared the distribution of scores before and after START training using the Wilcoxon signed-ranks test. We also used the Mann-Whitney $U$ test to compare the distributions of scores in the same period between freshmen and seniors.

Most studies would make comparisons based on median scores, since these are nonparametric tests. However, we decided to primarily use mean scores, which are easier to understand, and reflect the fact that our data are based on the number of correct answers, and show the median scores in parentheses.

We also calculated the number of students who answered each question correctly and the accuracy rate for each question by class standing before and after the training, examining the examples in which students tended to make mistakes.

\section{Results}

Table 2 compares the mean and median scores of freshmen and seniors on the triage exercise both before and after START education. We found that seniors had a mean (median) score of $23.5(24) \pm 0.7$ (out of a perfect score of 30) before the lecture and 29.3 (30) \pm 0.2 after the lecture, a significant increase $(p=0.0001)$. Likewise, freshman students had a mean (median) score of $17.4(18) \pm 0.6$ before the lecture and $29.1(30) \pm$ 0.3 after $(p=0.0001)$. In other words, we observed a remarkable change in both groups. Moreover, this marked improvement was more drastic among freshmen than among seniors: while the average number of correct answers increased by 5.8 among seniors, the average among freshmen increased by 11.7 points. 
$<$ Table 2> Comparison of mean/median score before and after START education in the two groups using Wilcoxon signed-rank test

\begin{tabular}{cccccc}
\hline & Before START education & After START education & \\
\cline { 2 - 5 } & Mean \pm SE & Median & Mean \pm SE & Median & p-value \\
\hline Seniors & $23.5 \pm 0.7$ & 24 & $29.3 \pm 0.2$ & 30 & 0.0001 \\
Freshmen & $17.4 \pm 0.6$ & 18 & $29.1 \pm 0.3$ & 30 & 0.0001 \\
\hline
\end{tabular}

$<$ Table 3> Comparing students' triage ability before and after START education using Mann-Whitney's U test

\begin{tabular}{cccccc}
\hline & \multicolumn{2}{c}{ Seniors } & \multicolumn{2}{c}{ Freshmen } & \\
\cline { 2 - 4 } & Mean $\pm \mathrm{SE}$ & Median & Mean $\pm \mathrm{SE}$ & Median & p-value \\
\hline $\begin{array}{c}\text { Before } \\
\text { education } \\
\begin{array}{c}\text { After } \\
\text { education }\end{array}\end{array}$ & $23.5 \pm 0.7$ & 24 & $17.4 \pm 0.6$ & 18 & 0.0001 \\
\hline
\end{tabular}

Table 3 compares freshmen and seniors' number of correct answers before and after START training. Before the training, the mean (median) $\pm \mathrm{SE}$ was $17.4(18) \pm 0.6$ for freshmen and $23.5(24) \pm 0.7$ for seniors, showing that seniors did significantly better $p=$ $0.0001)$. After the training, the mean (median) $\pm \mathrm{SE}$ was $29.1(30) \pm 0.3$ for freshmen and $29.3(30) \pm 0.2$ for seniors; there was no significant difference.

Table 4 shows the number of students who answered each question correctly and the accuracy rate for triage cases before and after the training for both freshmen and seniors. Before START education, both freshmen and seniors had less than a 50\% accuracy rate for both Cases 10 ("radial artery damage") and 12 ("facial burn"). After the training, the accuracy for these cases increased to $95 \%$ or higher for both classes. Other cases did not have as steep of an increase in accuracy. For example, the accuracy rate for Case 4 ("abdominal injury with intestinal tract hernia") remained at $88 \%$ for freshmen and $86 \%$ for seniors even after the training. Freshmen also had a low accuracy rate $(86 \%)$ for Case 24 ("Pregnant, water broke"), even after the training. However, overall, both freshmen and seniors had a total accuracy rate of $95 \%$ or higher after START education. 
$<$ Table $4>$ Student accuracy rate before and after START education

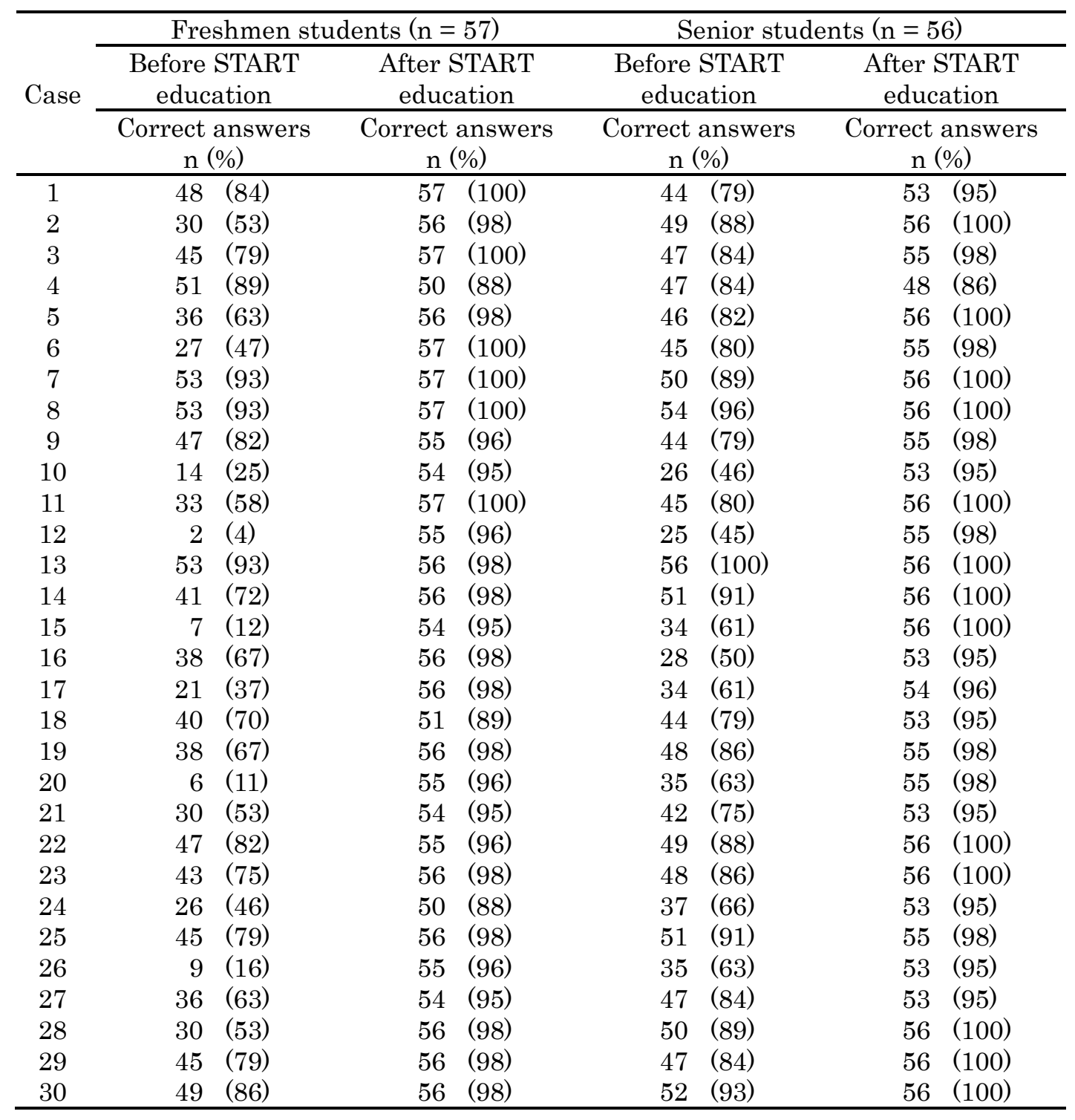

Note: \%; Accuracy rate.

\section{Discussion}

Our use of videos in START training was very effective, as shown by the increased total scores among both freshmen and seniors after the training. As expected, seniors' initial scores were higher: this makes sense, since they have accumulated nursing knowledge over three years that the freshmen, who have only been in college for about six months, do not have. However, it is interesting that the accuracy rate of both groups improved to almost $100 \%$ after the training. This implies that teaching the START method to nursing students was so effective that it could enable freshmen, who have almost no knowledge of medicine and nursing, to achieve an almost perfect score. In other words, using videos and 
presenting simulated patient cases is an effective method of triage education, perhaps because it is easier for students to imagine patients' conditions.

We also examined the problems that students tended to get wrong even after the training. Cases 10 and 12, both of which had an accuracy rate of $50 \%$ or lower among freshmen and seniors before the training, are similar in many ways. Both were medical conditions that looked worse than they were: while bleeding and a burned face may initially appear to be severe, both of these patients had stable vital signs. As noticed in our previous studies (Aknaga, Shibayama, Takahashi et al., 2017), freshmen may tend to over-triage, classifying the case based on appearances rather than vitals and other observations. However, this tendency decreased after the training: the accuracy rate for Case 10 increased to $95 \%$ among both freshmen and seniors, and that of Case 12 increased to $96 \%$ for freshmen and $98 \%$ for seniors.

Other cases remained difficult even after the training, even as the overall accuracy rate reached $95 \%$ or higher. (For a detailed qualitative study of the cases in which students continue to make mistakes, please see our other article, Aknaga, Shibayama, Takahashi et al., 2017.) For example, the accuracy rate of Case 4 was $88 \%$ for freshmen and $86 \%$ for seniors after the training. This case may have been slightly difficult because the injuryabdominal injury with intestinal hernia-required the consideration of multiple vital signs when making a judgment. This was an example that even a doctor might have struggled with, so it makes sense that this was a difficult triage classification for nursing students. That said, many nursing students correctly triaged the above case; therefore, the START method has the potential to enable nursing students to correctly triage even the most difficult cases. This also implies that teaching START methods can dramatically improve the triaging ability even of those with little knowledge of medicine and nursing.

This study does have some limitations. First, our study only included 113 nursing students at the Saga University Faculty of Medicine, resulting in a relatively small sample size. Future studies should collect and analyze data from other nursing colleges. In addition, one doctor experienced in disaster medical care was responsible for all lectures and teaching in our study; future research may wish to compare curricula conducted by multiple faculty members, nursing teachers, etc.

There is also a concern that simulation-based education (i.e., video education) may be more limited in effect than practical training that includes actors who simulate triage victims, allowing students to engage in real-life physical examinations. However, such methods are time-consuming and expensive, and realistically, videos are much more likely to be used in such situations. In addition, studies have found that virtual simulations (i.e., videos) can be as effective as practical training in helping students improve their triage skills (Ingrassia, Ragazzoni, Carenzo et al., 2015). 
Our findings are in line with others that find the START method to be useful among nursing students. Sapp, Brice, Myers et al. (2010) studied the triage accuracy of freshmen students using the START method and found them to be as accurate as emergency physicians and nurses. However, Sapp's study does not compare accuracy rates before and after START education. Claudius, Kaji, Santillanes et al. (2015) also reported on the usefulness of JumpSTART for medical students. Our study is also the first to quantitatively evaluate the effectiveness of START education among nursing students, especially using videos.

We found that the START method, an internationally standardized simple triage method, has the potential to greatly improve prehospital care. In Japan, where large natural disasters occur frequently, triage education for nursing students is important to save as many lives as possible after a disaster and should be included as early as possible in the college curriculum. In addition, our results suggest that this method may also be effective for the general public or for others with less medical knowledge. Educating the public as to the START method may therefore also help a community in the aftermath of a large natural disaster.

\section{Conclusion}

Our study demonstrates that teaching the START method to nursing students can dramatically improve their ability to triage. Using videos and simulated patients is an effective educational tool. After START education, even freshmen with very limited medical knowledge, increased their accuracy rate to $95 \%$ or more, and the cases that were often missed were those that were difficult even for doctors. Our results suggest that this method may also be effective for the general public and for others with less medical knowledge.

\section{Acknowledgments}

We would like to express our deepest gratitude to the students for participating in this study. We also thank Prof. Masahiro Nakano (Junshin Gakuen University) for his kind advice regarding statistical analysis, and Editage (www.editage,jp) for English language editing. This work was supported in part by a Grant-in-Aid for Scientific Research (C) (No.16K11946) from Japan's Ministry of Education, Culture, Sports, Science, and Technology. The authors have no financial conflicts of interest to declare. 


\section{References}

1) Kazuyuki AKINAGA, Masaru TAKAHASHI, Akiko SAKAMOTO, Setsuko UMEZAKI, Hitomi MATSUNG, \& Koichi SHINCHI (2012) Educational Effect of the Triage Training and Keeping Knowledge of the Education After One Year. Journal of Biomedical Fuzzy Systems Association, 14(2), 7-13. doi: 10.24466/jbfsa.14.2_7.

2) Kazuyuki AKINAGA, Kaoru SHIBAYAMA, Koichi TAKAHASHI, Setsuko UMESAKI, \& Koichi SHINCHI (2017) Study on Triage Education for Nursing Students: Analysis of Their Errors in Triage. Asian Journal of Human Services, 13, 10-22. doi: 10.14391/ajhs.13.10.

3) Mark BENSON, Kristi L. KOENING, \& Carl H. SCHULTZ (1996) Disaster Triage: START, Then SAVE-A New Method of Dynamic Triage for Victims of a Catastrophic Earthquake. Prehospital Disaster Medicine, 11(2), 117-124. doi: 10.1017/S1049023X0004276X.

4) Laura BRANNIGAN, Stephanie WITWER, Piper RUDEL, \& Alisa YOUNG (2006) Simulation Education in Mass-Casualty Incident Preparedness, Clinical Simulation in Nursing Education, 2, e69-e74. doi: 10.1016/j.ecns.2009.05.027.

5) Ilene ClAUdIUS, Amy H. KAJI, Genevieve SANTILLANES, Mark X. CICERO, J. Joelle DONOFRIO, Marianne GAUSCHE-HILL, et al.(2015) Accuracy, Efficiency, and Inappropriate Actions Using JumpSTART Triage in MCI Simulations. Prehospital Disaster Medicine, 30(5), 457-460. doi: 10.1017/S1049023X15005002.

6) Nancy Stephens DONATELLI \& Joan SOMES (2012) Disaster Planning Considerations Involving the Geriatric Patient: Part II. Journal of Emergency Nursing, 38, 563-567. doi: 10.1016/j.jen.2012.07.016.

7) Victor DUARTE \& Linda C. HAYNES (2006) Disaster Preparedness: "As Common As CPR." Clinical Simulation in Nursing Education, 2, e53-e57.

doi: 10.1016/j.ecns.2009.05.022.

8) Cathleen A. EVANS \& Mary BAUMBERGER-HENRY (2014) Readiness: How Prepared Are You? Journal of Emergency Nursing, 40, 448-452. doi: 10.1016/j.jen.2014.03.006.

9) Cynthia L. FORONDA, Keith SHUBECK, Sandra M. SWOBODA, Krysia Warren HUDSON, Chakra BUDHATHOKI, Nancy SULLIVAN, et al. (2016) Impact of Virtual Simulation to Teach Concepts of Disaster Triage. Clinical Simulation in Nursing, 12, 137-144. doi: 10.1016/j.ecns.2016.02.004.

10) Yumi FUKUYAMA, Koichi SHINCHI, Toyoka SHINCHI, Yumi MATAUZAKI, Mamiko FURUKAWA, Masashi TAKAMURA, et al. (2006) The Role of Nurses in International Disaster Relief Operations: Survey among Participants. Journal of International Health, 21(3), 169-175. 
11) Mamiko FURUKAWA, Koichi SHINCHI, Yumi FUKUYAMA, Toyoka SHINCHI, Masashi TAKAMURA, Koki KAKU, et al. (2007) The Role of Nurses in International Disaster Relief Operations: Survey Among Japanese Doctors and Nurses. Japanese Journal of Disaster Medicine, 12, 152-159.

12) Linda GOOD (2008) Ethical Decision Making in Disaster Triage. Journal of Emergency Nursing, 34, 112-115. doi: 10.1016/j.jen.2007.04.014.

13) Patricia Kunz HOWARD \& Andi L. FOLEY (2014) Disaster Triage-Are You Ready? Journal of Emergency Nursing, 40, 515-517. doi: 10.1016/j.jen.2014.05.010.

14) Pier Luigi INGRASSIA, Luca RAGAZZONI, Luca CARENZO, Davide COLOMBO, Alba Ripoll GALLARDO, \& Francesco Della CORTE (2015) Virtual Reality and Live Simulation: A Comparison between Two Simulation Tools for Assessing Mass Casualty Triage Skills. European Journal of Emergency Medicine, 22(2), 121-127. doi: 10.1097/MEJ.0000000000000132.

15) Akina ISHIBASHI, Yumi FUKUYAMA, Kazue NONAKA, \& Koichi SHINCHI (2017), The Role of Surgical Nurses in International Disaster Response in Japan: Recognition of Medical Workers with Experience in IDR. Asian Journal of Human Services, 13, 23-35. doi: 10.14391/ajhs.13.23.

16) Kayoko KAWAHARA \& Chie ISHIDA (2008) Disaster Triage Simulation Education Manual (DVD), Tokyo Metropolitan University, Benesse Cooperation.

17) Hitomi MATSUNAGA, Kazuyuki AKINAGA, Setsuko UMEZAKI, \& Koichi SHINCHI (2013) Required Condition, Information, and Knowledge for Participating in Disaster Relief Activities. Journal of Biomedical Fuzzy Systems Association, 15(1), $1-6$.

18) Hitomi MATSUNAGA, Koichi SHINCHI, Kazuyuki AKINAGA, \& Setsuko UMEZAKI (2013) Recognition of the Necessity of Practical Disaster Nursing Education among Nursing Teachers in Japan. Asian Journal of Human Services, 4, 30-39.

19) Norihito NOGUCHI, Satoshi INOUE, Chisato SHIMANOE, Shibayama KAORU, \& Koichi SHINCHI (2016) Factors Associated with Nursing Activities in Humanitarian Aid and Disaster Relief. PLoS One, 11(3), doi: 10.1371/journal.pone.0151170.

20) Norihito NOGUCHI, Satoshi INOUE, Chisato SHIMANOE, Kazuyuki AKINAGA, Miki UENO, Haruna TAKAHASHI, et al.(2017) Deployment-related Difficulties of Japanese Disaster Relief Workers by Mission Duration: A Cross-Sectional Study. Health Emergency and Disaster Nursing, 1(8), doi: 10.24298/hedn.2016-0019

21) Matthew F. POWERS (2007) Evaluation of Hospital-Based Disaster Education. Journal of Emergency Nursing, 33, 79-82. doi: 10.1016/j.jen.2006.10.008.

22) Akiko SAKAI \& Shizuko KIKUCHI (2016) Triage (p. 152-172 in Disaster Nursing) Nankodo Co: Tokyo, Japan (in Japanese). 
23) Robert F. SAPP, Jane H. BRICE, J. Brent MYERS, \& Paul R. HINCHEY (2010) Triage Performance of First-Year Medical Students Using a Multiple-Casualty Scenario, Paper Exercise. Prehospital Disaster Medicine, 25(3), 239-245. doi: 10.1017/S1049023X00008104.

24) Joan SOMES \& Nancy Stephens DONATELLI (2014) Ethics and Disaster Involving Geriatric Patients. Journal of Emergency Nursing, 40, 493-496. doi: 10.1016/j.jen.2014.05.013.

25) U.S. Department of Health and Human Services(2018) START Adult Triage Algorithm. Radiation Emergency Medical Management: REMM. http://www.remm.nlm.gov/startadult.htm (Accessed on March 18, 2018). 
- Editorial Board -

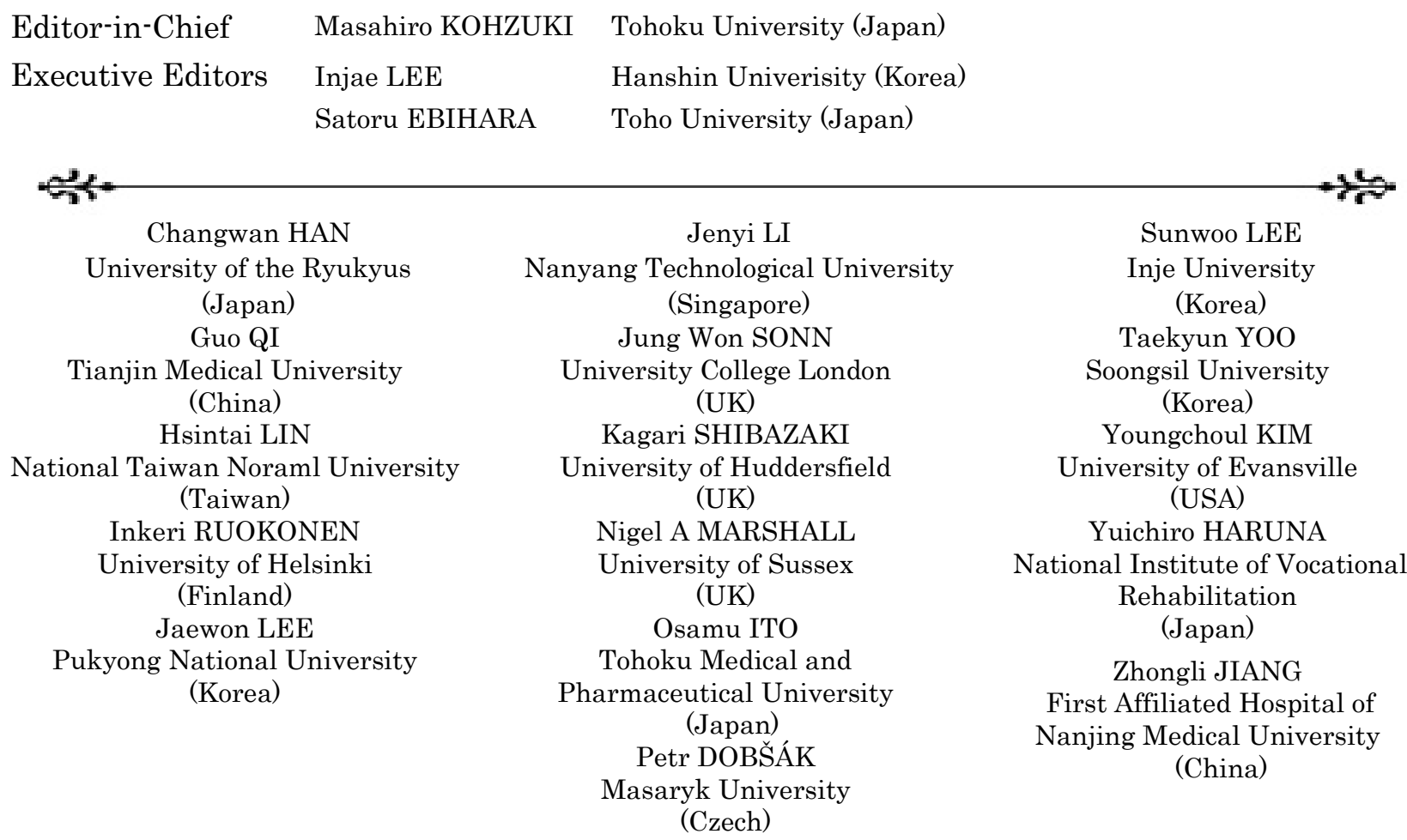

Editorial Staff

- Editorial

Assistants
Aiko KOHARA

Marcus Eije Zantere

Moonjung KIM
University of the Ryukyus (Japan)

University of Gothenburg (Sweden)

Korea Labor Force Development Institute for the aged (Korea)

Natsuki YANO

Tohoku University / University of the Ryukyus (Japan)

\section{Asian Journal of Human Services VOL.15 Ocober 2018}

(C) 2018 Asian Society of Human Services

$\begin{array}{ll}\text { Editor-in-Chief } & \text { Masahiro KOHZUKI } \\ \text { Presidents } & \text { Masahiro KOHZUKI } \cdot \text { Sunwoo LEE } \\ \text { Publisher } & \text { Asian Society of Human Services } \\ & \text { Faculty of Education, University of the Ryukyus, 1 Senbaru, Nishihara, Nakagami, Okinawa, Japan } \\ & \text { FAX: +81-098-895-8420 E-mail: ashs201091@gmail.com }\end{array}$

Production Asian Society of Human Services Press

Faculty of Education, University of the Ryukyus, 1 Senbaru, Nishihara, Nakagami, Okinawa, Japan FAX: +81-098-895-8420 E-mail: ashs201091@gmail.com 


\section{Asian Journal of Human Services \\ VOL.15 October 2018 \\ CONTENTS}

\section{ORIGINAL ARTICLES}

Using Videos to Analyze the Effectiveness of START Education for Japanese Nursing Students

Kazuyuki AKINAGA et al., 1

Effects of the OSCE to Motivate Students to Learn Before Clinical Practice

Yuko FUJIO et al., 13

The Current Status and Its Implications of Public-Private Partnerships for Official Development

Assistance in Korea: Focusing on Disability-Inclusive Development Cooperation

Juhee HWANG et al., 25

Effects of a Structured 8-week Nordic Walking Exercise Program on Physical Fitness in the Japanese Elderly

Study of "Individuality" on Nursing Care Job

Kimiko YAMAMOTO et al., 38

Kimiko YAMAMOTO et al., 52

\section{SHORT PAPERS}

A Comparison of the Factor Structure of the Self-Harm Antipathy Scale and related Demographic Characteristics between Korea and Japan

Yoshimi AOKI et al., 66 Issues of Specific Educational Curriculum Development for Resource Rooms and Special Needs Classes in Japanese High Schools

Mitsuyo SHIMOJO et al., 76

\section{REVIEW ARTICLES}

Importance of Physical Activity and $\dot{\mathrm{V}}_{2}$ max: Five Major Determinants of $\dot{\mathrm{V}}_{2} \max$

Masahiro KOHZUKI et al., 85

Importance of Physical Exercise in Oldest-old Adults: A Literature Review Study

Chaeyoon $\mathrm{CHO}$ et al., 93

Published by

Asian Society of Human Services

Okinawa, Japan 